\title{
The Wellbeing Thermometer: A Novel Framework for Measuring Wellbeing
}

\section{Marios Adamou ${ }^{1 *}$, Andrew Goddard ${ }^{2}$, Niki Kyriakidou3 ${ }^{3}$, Andrew Mooney4, Donal 0’Donoghue², Shriti Pattani ${ }^{5}$, Matthew Roycroft ${ }^{6}$}

${ }^{1}$ University of Huddersfield, Huddersfield, UK

${ }^{2}$ Royal College of Physicians, London, UK

${ }^{3}$ Leeds Beckett University, Leeds, UK

${ }^{4}$ Consultant Renal Physician, Renal Unit, St James's University Hospital, Leeds, UK

${ }^{5}$ London North West University Healthcare NHS Trust, London, UK

${ }^{6}$ Sheffield Teaching Hospitals NHS Foundation Trust, Sheffield, UK

Email: `m.adamou@nhs.net, N.Kyriakidou@leedsbeckett.ac.uk, andrew.mooney2@nhs.net,

Donal.ODonoghue@rcplondonn.ac.uk,matthew.roycroft@nhs.net

How to cite this paper: Adamou, M., Goddard, A., Kyriakidou, N., Mooney, A., O’Donoghue, D., Pattani, S., \& Roycroft, M. (2020). The Wellbeing Thermometer: A Novel Framework for Measuring Wellbeing. Psychology, 11, 1471-1480.

https://doi.org/10.4236/psych.2020.1110093

Received: September 11, 2020

Accepted: October 12, 2020

Published: October 15, 2020

Copyright (c) 2020 by author(s) and Scientific Research Publishing Inc. This work is licensed under the Creative Commons Attribution International License (CC BY 4.0).

http://creativecommons.org/licenses/by/4.0/

\begin{abstract}
Background: In recent years, there has been a concerted effort to acknowledge the effect the working environment has on health professionals in the UK. Several institutions have produced reports either commenting on the current status of the situation or pointing to a future direction. Still, practically it is unclear how much difference these intentions have made to the lives of health professionals. Method: One of the main obstacles in advancing this agenda is that without knowing what well-being is and how to measure it, a person cannot modify it. A multidisciplinary team of experts set as a task to develop a new theoretical framework of well-being accompanied by a tool to measure it hence affording the individual better knowledge and more control of their state of wellbeing. The development of this framework took three steps: understanding the concept of wellbeing from existing literature by reviewing all available tools to identify gaps and weaknesses, constructing a new framework for wellbeing and devising a set of questions to measure it. Results: The result of this work was a framework suggesting that wellbeing is determined by the domains of health, thoughts emotions, spiritual and social along with 25 questions (five for each domain) the answers to which are given an indication of a person's wellbeing status. Conclusion: The current models of wellbeing are limited. They are grounded either on concepts of mental illness such as major depressive disorder or single functions such as psychological or social. We propose that a new framework for wellbeing is required which is more holistic to enable professionals to develop "Wellbeing Intelligence".
\end{abstract}




\section{Keywords}

Stress at Work, Burnout, Wellbeing, Resilience, Occupational Stress

\section{Introduction}

In recent years, there has been a concerted effort to acknowledge the effect the working environment has on health professionals in the United Kingdom (UK). Several institutions have produced reports either commenting on the current status of the situation or pointing to a future direction. Still, practically we are unclear about how much difference these intentions have made to the lives of health professionals.

For example, National Health Service (NHS) England asserts that NHS staff "will get the backing they need" (NHS, 2019) mainly through workforce planning interventions which will take years to bear fruit. Health Education England wishes to "future proof the workforce" and make the NHS a more inclusive "family-friendly" employer, but their plans are still in consultation (Health Education England, 2017). NHS England, NHS Improvement and NHS Employers have developed an "NHS workforce health and wellbeing framework" for all NHS organisations (NHS Employers, 2019) advising prevention and self-management as well as targeted support to be delivered through NHS Trusts; it is again not clear how much that advice has filtered through.

In the meantime, physician burnout remains a significant concern (Collier, 2017); pressures in the system are immense for both doctors and nurses (British Medical Association, 2019; The House of Commons Health Select Committee, 2018) with sickness absence in the NHS in England (3.4\%) being twice the rate of that in the private sector (1.7\%). Previous research has shown that $50 \%$ more NHS staff in England report debilitating levels of work stress compared to the general working population (West, Dawson et al., 2011) and national staff survey findings in England, Northern Ireland and Wales indicate that between 37\% and $40 \%$ of staff each year report being unwell because of work stress during the previous year (West \& Coia, 2019).

Being aware of these challenges, we wanted to develop a new method by which to measure the wellbeing of an individual with the view of health professionals developing "Wellbeing Intelligence". The outcome of this would be to empower health professionals to manage their wellbeing. This approach to self-management has its basis in the locus of control theory (Rotter, 1954) which also suggests that there are benefits to having an internal locus of control (Rotter, 1966), particularly with problem-solving and conflict management (Dijkstra, Beersma et al., 2011). Our view is that if people feel they have control over their wellbeing; they can take action to improve it (Fishbein \& Ajzen, 1975).

In terms of definitions, the word wellbeing is a "floating signifier" (Lévi-Strauss, 1950) suggesting that the word itself is more stable than the concept because 
people have different views about what wellbeing means to them. Amongst the many definitions of wellbeing in the literature, we chose one précising description which is simple and practical: wellbeing can be understood as how people feel and how they function on a number of levels and how they evaluate their lives as a whole. At this stage, it is worth pointing out that wellbeing is not the same as "happiness". This latter concept is commonly linked with external factors such as luck or fortune (Oishi, Graham et al., 2013), moment to moment feelings of excitement (Mogilner, Kamvar et al., 2011) or peacefulness (Tsai, Knutson et al., 2006) and does not always tell us about how a person evaluates their lives as a whole or about how they function in the world. Wellbeing is a much broader concept than moment-to-moment happiness: it includes happiness but also other things such as how satisfied people are with their lives as a whole, and things such as autonomy (having a sense of control over your life) and purpose (having a sense of purpose in life).

The concept of wellbeing is also different from the Quality of Life (QOL) or Health-Related Quality of Life (HRQOL); QOL encompasses more things than HRQoL. Quality of life is defined by the World Health Organisation (WHO) as "individuals' perceptions of their position in life in the context of the culture and value systems in which they live and in relation to their goals, expectations, standards and concerns" (WHO, 1995). This is a broad concept (Schalock \& Siperstein, 1996) which can be affected by external economic, social public policy, social legislation, and community programs (Nussbaum \& Sen, 1993) and not so much by individual factors. There are many general instruments available to measure quality of life and the WHO has developed a quality of life instrument, the WHOQOL, which captures many subjective aspects of quality of life (Group, 1994). In recent years, QOL instruments have been acknowledged as very important in the evaluation of health care (WHO, 1993) leading to the development of Health-Related Quality of Life (HRQOL) measures, some of which are disease-specific and some of which, such as the EQ-5D, which are not (Rabin \& Charro, 2001). Their function, which is to measure "perceptions of health", is very much different from what we were aiming to capture which is "how people feel and function and evaluate their lives as a whole".

Another term that we thought important to mention is that of psychological resilience. Resiliency inquiry did not emerge from academic grounding in theory, but rather through the phenomenological identification of characteristics of survivors, mostly young people, living in a high-risk situation (Richardson, 2002). Through three waves of inquiry, the concept of resilience emerged, and this refers to a set of psychological and behavioural capabilities which allow an individual to survive adversity.

\section{Methods}

The development of the tool was done in three stages. The first stage included a literature review and critical analysis of existing wellbeing tools. The second step drew on the core principles of Participatory Action Research, with the authors 
engaging in data collection, reflection and action (Baum, MacDougall et al., 2006) to develop the new framework for wellbeing. The third phase involved developing a set of questions to measure wellbeing based on the new framework. This latter stage had two substages: 1) creating a bank of questions based on existing literature and own opinion for each wellbeing subdomain and 2) selecting the questions to trial.

The questions were designed in a manner meeting appropriate questionnaire standards (Sudman, Bradburn et al., 1982; Gillham, 2007). The above process was conducted through email correspondence and face to face meetings of the authors between February 2019-August 2019.

\section{Results}

\subsection{Reviewing Existing Wellbeing Tools}

The most prominent wellbeing tool we found in use was the Warwick-Edinburgh Mental Well-being Scale (WEMWBS) (Tennant, Hiller et al., 2007). This is a 14 item positively worded scale with five response categories and covers most aspects of positive mental health (positive thoughts and feelings) currently in the literature, including both hedonic and eudemonic perspectives. We found this tool was too narrow to measure other components required for wellbeing such as social and spiritual domains.

The Personal Wellbeing Index (PWI) was created from the Comprehensive Quality of Life Scale (ComQol) (Cummins, McCabe et al., 1994) and is a self-report scale which measures the subjective dimensions of quality of life (Lau, Cummins et al., 2005). It, however, consists of seven items corresponding to seven domains of life satisfaction rather than forming a unitary concept of wellbeing.

The World Health Organisation created the Five Well-Being Index (WHO-5) (Topp, Ostergaard et al., 2015) which is a short self-reported measure derived from the WHO-10 (Bech, Gudex et al., 1996) but its layout follows that of the Major Depression Inventory which measures the WHO/ICD-10 symptoms of major depressive disorder and not wellbeing. There is also a tool created specifically for physicians called the Physician Well-Being Index (PWBI), but this has its basis in measuring distress (Dyrbye, Satele et al., 2013) (fatigue, depression, burnout, anxiety/stress, and mental/physical QOL) having originally done so with medical students (Dyrbye, Schwartz et al., 2011) rather than being able to capture eudemonic perspectives.

Other wellbeing tools focused on mental health (Goldberg \& Williams, 2000), affect (Bradburn, 1969), ontological needs (Hyde, Wiggins et al., 2003) and basic psychological needs (Johnston \& Finney, 2010). Ryff (Ryff, 1989) proposed a theoretical model of psychological wellbeing comprising of six different aspects of positive functioning namely autonomy, environmental mastery, personal growth, purpose in life, positive relations with others and self-acceptance. This model was developed based on a study of human functioning (Ryff, 1989) but did not include other components such as spiritual. 
Based on hedonism, Diener (Diener, 2000) proposed the construct of Subjective Wellbeing (SWB) which refers to an individual's affective and cognitive evaluations of life. They argued that the feeling of happiness and satisfaction with life is universal, even though what brings about happiness and satisfaction may differ across societies and cultures (Diener, Diener et al., 2009).

\subsection{Developing a New Framework for Wellbeing}

Having considered these tools and particularly their limitations, we concluded a new model of wellbeing fitting our definition was required as a way to introduce a more holistic approach. We noted that the tools mentioned above were initially created by their authors following a model which was constructed based on a theoretical framework and validated later. A prime example of this methodology is the creation of the Model of Human Occupation Screening Tool (MOHOST). The model is based on the theoretical premise that occupational performance is a central force in health, wellbeing, development and change. Based on this theoretical premise, a model was created, which views humans as dynamic, self-organising systems always unfolding and changing in time (Parkinson, Forsyth et al., 2004). Following the creation of the model, a tool was developed to measure occupational functioning.

The theoretical premise for our understanding of wellbeing developed from the latest knowledge on the topics of human nature and personality. Human nature is defined as a bundle of characteristics, including ways of thinking, feeling, and acting, which all humans are said to have naturally in common (Downes \& Machery, 2013) whilst personality refers to the pattern of an individual person's thoughts, feelings, social adjustments, and behaviours consistently exhibited over time that strongly influences one's expectations, self-perceptions, values, and attitudes (Friedman \& Schustack, 2016). When developing our model of wellbeing our goal was to structure it in such a way as to be 1) objective, 2) inclusive, 3) individualised, 4) agent-relative, 5) self-directed 6) social.

From this basis, we developed a model which views human wellbeing as emerging from the following five domains: health, thoughts, emotions, spiritual and social. This framework is supported by literature which studied these domains in isolation. For example, the effect to the wellbeing of health (Mandolesi, Polverino et al., 2018), thoughts (Stewart, Ware et al., 1992; Andrews-Hanna, Kaiser et al., 2013), emotions (Bradburn, 1969; Diener, 1984), spiritual (Ellison, 1983; Bredle, Salsman et al., 2011) and social (Sarason, Levine et al., 1983; Coulthard, Johnson et al., 2011) have been well documented and also alluded to above in the literature presented.

\subsection{Developing Questions to Measure Wellbeing}

Having established our model of wellbeing, the next step was to develop appropriate questions which would quantify the responses relating the domains we identified. Having been informed by reviewing questions used to measure wellbeing linked to the domains we selected (Bradburn, 1969; Ellison, 1983; Sarason, 
Levine et al., 1983; Diener, 1984; Stewart, Ware et al., 1992; Bredle, Salsman et al., 2011; Coulthard, Johnson et al., 2011; Andrews-Hanna, Kaiser et al., 2013; Mandolesi, Polverino et al., 2018), we brought these together and created our own initial list of fifty questions which we then reduced to twenty-five for convenience and accuracy. The questions are not listed here as to protect any copyright which may arise.

\section{Discussion}

The wellbeing of healthcare professionals is getting higher in the agenda of policy makers and for a good number our reasons. Our reason behind taking an interest in wellbeing particularly in healthcare professionals is first because it is a requirement for their health. Since its inception, the World Health Organisation (WHO) included mental wellbeing in its definition of health as "a state of complete physical, mental and social wellbeing and not merely the absence of disease or infirmity" (WHO, 2001). Lack of mental wellbeing, as an individual attribute (WHO, 2012), is a risk factor for mental illness and improvements in mental wellbeing confer resilience to the stressful life events which can be a cause of mental illness in adult life. Mental wellbeing is also associated with better physical health and longevity (Chida \& Steptoe, 2008; Howell, 2009) so an improvement of mental wellbeing is a valuable goal in its own right.

Another reason for taking an interest in wellbeing is because it has benefits for patients and the wider healthcare system. A report by the General Medical Council which reviewed revenant research on the effects of wellbeing asserts that "staff wellbeing significantly improves productivity, care quality, patient safety, patient satisfaction, financial performance and the sustainability of our health services" (West \& Coia, 2019).

Finally, we theorise that professionals whose wellbeing is affected, may be at risk of "burnout" and even mental illness. Burnout is a syndrome of emotional exhaustion and cynicism which frequently occurs among individuals who do "people work" of some kind (Maslach \& Jackson, 1981). It follows a three-component conceptualisation (Maslach, 1982) of exhaustion, depersonalisation and diminished personal accomplishment and is a type of chronic stress in response to stressful work conditions (Ganster \& Schaubroeck, 1991). Understanding the burnout experience has been a challenge to psychiatrists (Maslach \& Leiter, 2016) and may be linked to a higher incidence of mental illness (Fitzpatrick, Biesma et al., 2019). We believe that by intervening in the stage where the wellbeing of professionals is affected, the risk of entering the burnout and illness stage will be reduced.

Wellbeing is an emergent state and as such would be constituted by inetrelated parts which contribute to the creation of that state (Goldstein, 1999). Emergence is appealed to when the configuration of the components of a complex system offers more explanatory insight into the dynamics of the system than do explanations based on the parts alone. The existing models of wellbeing we reviewed focused more on a single part (for example psychological or social) and 
therefore lent themselves to a much more limited model of wellbeing than the one which we propose. Our model of wellbeing proposes that this state emerges as a result of domains operating as parts of a complex adaptive system. By identifying these parts we are able to measure them and by extension, have a way to intervene so the state of person's wellbeing can be increased.

\section{Conclusion}

The current models of wellbeing are limited. They are grounded either on concepts of mental illness such as major depressive disorder or single functions such as psychological or social. We propose that a new framework for wellbeing is required which is more holistic and developed a model in which this has five parts: health, thoughts emotions, spiritual and social domains.

We also propose that with a set of questions based on these parts a person's state of wellbeing can be measured. We developed such a tool and the next step for this process is to continue with a field evaluation. Preliminary studies are taking place within the healthcare field with the ultimate aim of using these tools as a means to help health professionals develop "Wellbeing Intelligence".

\section{Conflicts of Interest}

The authors declare no conflicts of interest regarding the publication of this paper.

\section{References}

Andrews-Hanna, J., Kaiser, R., Turner, A., Reineberg, A., Godinez, D., Dimidjian, S., \& Banich, M. (2013). A Penny for Your Thoughts: Dimensions of Self-Generated Thought Content and Relationships with Individual Differences in Emotional Wellbeing. Frontiers in Psychology, 4, 900. https://doi.org/10.3389/fpsyg.2013.00900

Baum, F., MacDougall, C., \& Smith, D. (2006). Participatory Action Research. Journal of Epidemiology and Community Health, 60, 854-857. https://doi.org/10.1136/jech.2004.028662

Bech, P., Gudex, C., \& Johansen, K. S. (1996). The WHO (Ten) Well-Being Index: Validation in Diabetes. Psychotherapy and Psychosomatics, 65, 183-190. https://doi.org/10.1159/000289073

Bradburn, N. M. (1969). The Structure of Psychological Well-Being. Oxford: Aldine. https://doi.org/10.1037/t10756-000

Bredle, J. M., Salsman, J. M., Debb, S. M., Arnold, B. J., \& Cella, D. (2011). Spiritual Well-Being as a Component of Health-Related Quality of Life: The Functional Assessment of Chronic Illness Therapy-Spiritual Well-Being Scale (FACIT-Sp). Religions, 2, 77-94. https://doi.org/10.3390/rel2010077

British Medical Association (2019). Caring, Supportive, Collaborative: A Future Vision for the NHS.

Chida, Y., \& Steptoe, A. (2008). Positive Psychological Well-Being and Mortality: A Quantitative Review of Prospective Observational Studies. Psychosomatic Medicine, 70, 741-756. https://doi.org/10.1097/PSY.0b013e31818105ba

Collier, R. (2017). Physician Burnout a Major Concern. CMAJ: Canadian Medical Asso- 
ciation Journal, 189, E1236-E1237. https://doi.org/10.1503/cmaj.1095496

Coulthard, S., Johnson, D., \& McGregor, J. A. (2011). Poverty, Sustainability and Human Wellbeing: A Social Wellbeing Approach to the Global Fisheries Crisis. Global Environmental Change, 21, 453-463. https://doi.org/10.1016/j.gloenvcha.2011.01.003

Cummins, R. A., McCabe, M. P., Romeo, Y., \& Gullone, E. (1994). The Comprehensive Quality of Life Scale: Instrument Development and Psychometric Evaluation on Tertiary Staff and Students. Educational and Psychological Measurement, 54, 372-382. https://doi.org/10.1177/0013164494054002011

Diener, E. (1984). Subjective Well-Being. Psychological Bulletin, 95, 542-575. https://doi.org/10.1037/0033-2909.95.3.542

Diener, E. (2000). Subjective Well-Being. The Science of Happiness and a Proposal for a National Index. American Psychologist, 55, 34-43. https://doi.org/10.1037/0003-066X.55.1.34

Diener, E., Diener, M., \& Diener, C. (2009). Factors Predicting the Subjective Well-Being of Nations. In Culture and Well-Being (pp. 43-70). Berlin: Springer. https://doi.org/10.1007/978-90-481-2352-0_3

Dijkstra, M. T. M., Beersma, B., \& Evers, A. (2011). Reducing Conflict-Related Employee Strain: The Benefits of an Internal Locus of Control and a Problem-Solving Conflict Management Strategy. Work \& Stress, 25, 167-184. https://doi.org/10.1080/02678373.2011.593344

Downes, S. M., \& Machery, E. (2013). Arguing about Human Nature: Contemporary Debates. New York: Routledge.

Dyrbye, L. N., Satele, D., Sloan, J., \& Shanafelt, T. D. (2013). Utility of a Brief Screening Tool to Identify Physicians in Distress. Journal of General Internal Medicine, 28, 421-427. https://doi.org/10.1007/s11606-012-2252-9

Dyrbye, L. N., Schwartz, A., Downing, S. M., Szydlo, D. W., Sloan, J. A., \& Shanafelt, T. D. (2011). Efficacy of a Brief Screening Tool to Identify Medical Students in Distress. Academic Medicine, 86, 907-914. https://doi.org/10.1097/ACM.0b013e31821da615

Ellison, C. W. (1983). Spiritual Well-Being: Conceptualization and Measurement. Journal of Psychology and Theology, 11, 330-338. https://doi.org/10.1177/009164718301100406

Fishbein, M., \& Ajzen, I. (1975). Beliefs Attitude, Intention, and Behavior: An Introduction to Theory and Research. Reading, MA: Addison-Wesley.

Fitzpatrick, O., Biesma, R., Conroy, R. M., \& McGarvey, A. (2019). Prevalence and Relationship between Burnout and Depression in Our Future Doctors: A Cross-Sectional Study in a Cohort of Preclinical and Clinical Medical Students in Ireland. BMJ Open, 9, e023297. https://doi.org/10.1136/bmjopen-2018-023297

Friedman, H., \& Schustack, M. (2016). Personality: Classic Theories and Modern Research. London: Pearson Education.

Ganster, D. C., \& Schaubroeck, J. (1991). Work Stress and Employee Health. Journal of Management, 17, 235-271. https://doi.org/10.1177/014920639101700202

Gillham, B. (2007). Developing a Questionnaire. London: Continuum.

Goldberg, D., \& Williams, P. (2000). General Health Questionnaire (GHQ). Swindon: NFER-Nelson.

Goldstein, J. (1999). Emergence as a Construct: History and Issues. Emergence, 1, 49-72. https://doi.org/10.1207/s15327000em0101_4

Group, W. (1994). Development of the WHOQOL: Rationale and Current Status. International Journal of Mental Health, 23, 24-56. 
https://doi.org/10.1080/00207411.1994.11449286

Health Education England (2017). Facing the Facts, Shaping the Future-A Draft Health and Care Workforce Strategy for England to 2027. Health Education England.

Howell, R. T. (2009). Review: Positive Psychological Well-Being Reduces the Risk of Mortality in Both Ill and Healthy Populations. Evidence-Based Mental Health, 12, 41. https://doi.org/10.1136/ebmh.12.2.41

Hyde, M., Wiggins, R. D., Higgs, P., \& Blane, D. B. (2003). A Measure of Quality of Life in Early Old Age: The Theory, Development and Properties of a Needs Satisfaction Model (CASP-19). Aging and Mental Health, 7, 186-194. https://doi.org/10.1080/1360786031000101157

Johnston, M. M., \& Finney, S. J. (2010). Measuring Basic Needs Satisfaction: Evaluating Previous Research and Conducting New Psychometric Evaluations of the Basic Needs Satisfaction in General Scale. Contemporary Educational Psychology, 35, 280-296. https://doi.org/10.1016/j.cedpsych.2010.04.003

Lau, A. L., Cummins, R. A., \& Mcpherson, W. (2005). An Investigation into the Cross-Cultural Equivalence of the Personal Wellbeing Index. Social Indicators Research, 72, 403-430. https://doi.org/10.1007/s11205-004-0561-z

Lévi-Strauss, C. (1950). Introduction à l'oeuvre de Marcel Mauss. Mauss, Sociologie et Anthropologie. Paris: Presses Universitaires de France.

Mandolesi, L., Polverino, A., Montuori, S., Foti, F., Ferraioli, G., Sorrentino, P., \& Sorrentino, G. (2018). Effects of Physical Exercise on Cognitive Functioning and Wellbeing: Biological and Psychological Benefits. Frontiers in Psychology, 9, 509. https://doi.org/10.3389/fpsyg.2018.00509

Maslach, C. (1982). Burnout: The Cost of Caring. Englewood Cliffs, NJ: Prentice-Hall.

Maslach, C., \& Jackson, S. E. (1981). The Measurement of Experienced Burnout. Journal of Organizational Behavior, 2, 99-113. https://doi.org/10.1002/job.4030020205

Maslach, C., \& Leiter, M. P. (2016). Understanding the Burnout Experience: Recent Research and Its Implications for Psychiatry. World Psychiatry, 15, 103-111. https://doi.org/10.1002/wps.20311

Mogilner, C., Kamvar, S. D., \& Aaker, J. (2011). The Shifting Meaning of Happiness. Social Psychological and Personality Science, 2, 395-402.

https://doi.org/10.1177/1948550610393987

NHS (2019). The NHS Long Term Plan.

NHS Employers (2019). Workforce Health and Wellbeing Framework. NHS Employers.

Nussbaum, M., \& Sen, A. (1993). The Quality of Life. Oxford: Clarendon Press. https://doi.org/10.1093/0198287976.001.0001

Oishi, S., Graham, J., Kesebir, S., \& Galinha, I. C. (2013). Concepts of Happiness across Time and Cultures. Personality and Social Psychology Bulletin, 39, 559-577. https://doi.org/10.1177/0146167213480042

Parkinson, S., Forsyth, K., \& Kielhofner, G. (2004). A User's Manual for the Model of Human Occupation Screening Tool (MOHOST). Model of Human Occupation Clearinghouse, Department of Occupational Therapy. https://doi.org/10.1037/t52666-000

Rabin, R., \& Charro, F. D. (2001). EQ-SD: A Measure of Health Status from the EuroQol Group. Annals of Medicine, 33, 337-343. https://doi.org/10.3109/07853890109002087

Richardson, G. E. (2002). The Metatheory of Resilience and Resiliency. Journal of Clinical Psychology, 58, 307-321. https://doi.org/10.1002/jclp.10020

Rotter, J. B. (1954). Social Learning and Clinical Psychology. New York: Prentice-Hall. 
https://doi.org/10.1037/10788-000

Rotter, J. B. (1966). Generalized Expectancies for Internal versus External Control of Reinforcement. Psychological Monographs, 80, 1-28. https://doi.org/10.1037/h0092976

Ryff, C. D. (1989). Happiness Is Everything, or Is It? Explorations on the Meaning of Psychological Well-Being. Journal of Personality and Social Psychology, 57, 1069-1081. https://doi.org/10.1037/0022-3514.57.6.1069

Sarason, I. G., Levine, H. M., Basham, R. B., \& Sarason, B. R. (1983). Assessing Social Support: The social Support Questionnaire. Journal of Personality and Social Psychology, 44, 127. https://doi.org/10.1037/0022-3514.44.1.127

Schalock, R. L., \& Siperstein, G. N. (1996). Quality of Life. Volume I: Conceptualization and Measurement. ERIC.

Stewart, A. L., Ware, J. E., Sherbourne, C. D., \& Wells, K. B. (1992). Psychological Distress/Well-Being and Cognitive Functioning Measures. In A. L. Stewart, \& J. E. Ware (Eds.), Measuring Functioning and Wellbeing (pp. 103-142). Durham and London: Duke University Press.

Sudman, S., Bradburn, N. M., \& Wansick, B. (1982). Asking Questions: A Practical Guide to Questionnaire Design. San Francisco, CA: Jossey-Bass.

Tennant, R., Hiller, L., Fishwick, R., Platt, S., Joseph, S., Weich, S., Parkinson, J., Secker, J., \& Stewart-Brown, S. (2007). The Warwick-Edinburgh Mental Well-Being Scale (WEMWBS): Development and UK Validation. Health and Quality of Life Outcomes, 5, 63.

https://doi.org/10.1186/1477-7525-5-63

The House of Commons Health Select Committee (2018). The Nursing Workforce: Second Report of Session 2017-19. House of Commons.

Topp, C. W., Ostergaard, S. D., Sondergaard, S., \& Bech, P. (2015). The WHO-5 Well-Being Index: A Systematic Review of the Literature. Psychotherapy and Psychosomatics, 84, 167-176. https://doi.org/10.1159/000376585

Tsai, J. L., Knutson, B., \& Fung, H. H. (2006). Cultural Variation in Affect Valuation. Journal of Personality and Social Psychology, 90, 288-307. https://doi.org/10.1037/0022-3514.90.2.288

West, M., \& Coia, D. (2019). Caring for Doctors Caring for Patients. London: General Medical Council.

West, M., Dawson, J., Dawson, J., Admasachew, L., \& Topakas, A. (2011). NHS Staff Management and Health Service Quality. Lancaster: Lancaster University Management School and the Work Foundation Aston Business School.

WHO (1993). Study Protocol for the World Health Organization Project to Develop a Quality of Life Assessment Instrument (WHOQOL). Quality of Life Research, 2, 153-159. https://doi.org/10.1007/BF00435734

WHO (1995). The World Health Organization Quality of Life Assessment (WHOQOL): Position Paper from the World Health Organization. Social Science \& Medicine, 41, 1403-1409. https://doi.org/10.1016/0277-9536(95)00112-K

WHO (2001). Basic Documents (p. 1). Geneva: World Health Organization.

WHO (2012). Risks to Mental Health: An Overview of the Vulnerabilities and Risk Factors. Geneva: World Health Organization. 